\title{
Desenvolvimento de espumas vítreas a partir de garrafa e casca de ovo
}

\author{
Foam glasses development from glass \\ bottles and eggshell
}

\author{
Fabrício Ravanello Mariosi ${ }^{1}$, Rubens Camaratta ${ }^{2}$, Fernando Machado Machado $^{2}$, \\ Luiz Fernando Rodrigues $\mathrm{Jr}^{3}$
}

\footnotetext{
${ }^{1}$ Curso de Engenharia de Materiais, Centro Universitário Franciscano, Santa Maria, Rio Grande do Sul, Brasil.

e-mail: fmariosi@hotmail.com

${ }^{2}$ Departamento de Engenharia de Materiais, Centro de Desenvolvimento Tecnológico/CDTec, Universidade Federal de, Pelotas, Rio Grande do Sul, Brasil. e-mail: rubenscamaratta@yahoo.com.br; fernando.machado.machado80@gmail.com.

${ }^{3}$ Curso de Engenharia Biomédica, Centro Universitário Franciscano, Santa Maria, Rio Grande do Sul, Brasil. e-mail: luiz.fernando@unifra.br
}

\section{RESUMO}

Este trabalho tem como foco a produção de espumas vítreas a partir de materiais reciclados, fazendo uso de matéria-prima de fácil acesso local e alta incidência no mercado: garrafas de cerveja não retornáveis e casca de ovo, como agente espumante. Para tanto, investigou-se a influência da temperatura de queima, da granulometria do vidro precursor e do percentual de agente espumante na expansão volumétrica dos corpos cerâmicos. Esses foram formulados com 3\% e 5\% em massa de agente espumante, utilizando vidros com granulometrias padronizadas por peneiras mesh \#100, \#200 e \#325, conformados em uma prensa uniaxial com 40 $\mathrm{MPa}$. Os corpos de prova foram queimados nas temperaturas de $700{ }^{\circ} \mathrm{C}, 800{ }^{\circ} \mathrm{C}$ e $900{ }^{\circ} \mathrm{C}$ com taxa de 2,5 ${ }^{\circ} \mathrm{C} / \mathrm{min}$. As espumas vítreas foram avaliadas por sua expansão volumétrica, densidade, diâmetros de poros e análise de difração de raios- X (DRX). Verificou-se grande importância da granulometria do vidro e temperatura de queima na formação da fase vítrea ideal para favorecimento da expansão volumétrica das espumas vítreas. O percentual de agente espumante influenciou na expansão, de modo que com $3 \%$ de agente espumante se obteve os maiores valores de expansão volumétrica. Fases cristalinas foram observadas nas amostras queimadas a $800{ }^{\circ} \mathrm{C}$ e $900{ }^{\circ} \mathrm{C}$ como sinal de desvitrificação.

Palavras-chave: Casca de ovo, expansão volumétrica, espumas vítreas.

\section{ABSTRACT}

The objective was the production of foam glasses obtained from glass bottles powder and eggshell as the foaming agent, thereby producing foam glasses composed entirely of recycled materials. Therefore, we investigated the influence of the sintering temperature, particle size of the glass and the foaming agent (wt \%) in the volumetric expansion of the samples. They were formulated by adding 3\% and 5\% of foaming agent , using a standardized particle size by sieves mesh \#100, \#200 and \#325, compressed in an uniaxially press (40 $\mathrm{MPa}$ ). The sintering was made between $700{ }^{\circ} \mathrm{C}$ and $900{ }^{\circ} \mathrm{C}$ with $2,5^{\circ} \mathrm{C} / \mathrm{min}$ rate. The characterization was made by volumetric expansion, density pore size and XRD (X-ray diffraction). It was verified the great importance of the glass particle size in the volume expansion of vitreous foams. The foaming agent influenced the percent expansion so that with $3 \%$ foaming agent was obtained the highest volumetric expansion values. Crystalline phases were observed for the samples burnt out at $800{ }^{\circ} \mathrm{C}$ and $900{ }^{\circ} \mathrm{C}$ as a signal of devitrification.

Keywords: Eggshell, volumetric expansion, foam glasses.

\section{INTRODUÇÃO}

Com o crescente aumento da população mundial, bem como suas necessidades de consumo, a indústria necessita sistematicamente aumentar sua produtividade. Dessa forma, grandes volumes de bens de consumo são gerados e incorretamente descartados após o uso, acarretando um elevado impacto ambiental. 
O Brasil produz, em média, 980 mil toneladas de embalagens de vidro por ano, usando cerca de $45 \%$ de matéria-prima reciclada na forma de cacos. Parte deles foi gerada como refugo nas fábricas e parte retornou por meio da coleta seletiva [1]. Dentre esses resíduos, destacam-se os à base de vidro, tais como garrafas, embalagens de alimentos, lâmpadas, monitores de computador e televisores. Dependendo da composição do vidro utilizado na manufatura desses produtos, existe uma grande dificuldade de reutilização e armazenamento após a vida útil. Essa dificuldade é justificada pelo alto teor de metais pesados presentes em algumas dessas composições que, quando expostas a intempéries, podem lixiviar [2].

No domínio da gestão de resíduos é fortalecido o conceito de recuperação e melhoria dos resíduos, resultantes de diferentes produções para a sua utilização em novos setores industriais. Nessa perspectiva, produção de espumas de vidro representa uma excelente oportunidade para absorver grandes quantidades de resíduos de vidro [3], as quais são obtidas pela adição de um agente espumante ao vidro moído e queimado em temperaturas acima do seu ponto de decomposição térmica [4]. A distribuição e tamanho dos poros, bem como estabilidade, são fatores importantes para a qualidade das espumas [5].

A maior expansão térmica das espumas vítreas e consequente menor densidade está atrelada a fatores importantes do processo de preparação da massa vítrea. Dessa forma, a captação na massa vítrea do $\mathrm{CO}_{2}$ formado é mais eficaz [6]. No processo de espumação são observados dois fenômenos em altas temperaturas: a decomposição do agente espumante gerando $\mathrm{CO}_{2}$ e a formação de líquido que, posteriormente, formará a fase vítrea. Segundo KONIG et al. [7], no processo de síntese de espumas vítreas a etapa de produção de $\mathrm{CO}_{2}$ é a mais importante. Sob elevada temperatura, a pressão exercida nos poros pelo $\mathrm{O}_{2}$ aumenta levando ao início da expansão [8]. Quando a pressão do gás excede as forças de tensão superficial e viscosidade, a parede do poro se estende, expandindo o poro. Existe uma relação inversamente proporcional entre o raio de um poro e sua pressão interna. Ou seja, a pressão é menor em poros grandes do que em poros pequenos. Como consequência, a maioria do $\mathrm{O}_{2}$ difunde das partículas para poros maiores, e elas crescerão mais rapidamente do que os poros menores. Uma vez que os poros grandes têm uma área de superfície maior, têm maior acessibilidade à difusão de $\mathrm{O}_{2}$ a partir da fusão do vidro. Isso contribui adicionalmente para uma taxa de crescimento mais rápida dos poros maiores [8].

A influência da granulometria do vidro no processo de espumação do corpo cerâmico pode ocorrer tanto na decomposição do agente espumante quanto no processo de formação de fase vítrea, visto que uma partícula menor apresenta maior reatividade, atuando nas reações químicas do silicato com o agente espumante, assim como diminuindo a temperatura necessária para sua fusão e vitrificação [9]. Atualmente, resíduos de cascas de ovos têm sido estudados na busca por tecnologias limpas e renováveis, tais como adsorção de metais pesados $[10,11]$ e síntese de fosfato de cálcio $[12,13]$.

Neste trabalho, cascas de ovos foram utilizadas, juntamente com vidro moído de garrafas, para a confecção de espumas vítreas. Espera-se que o uso dessas matérias-primas permita um elevado grau de espumação, por meio da decomposição térmica do $\mathrm{CaCO}_{3}$ da casca de ovo, juntamente com o pó de vidro utilizado. Além disso, é aguardado que o controle do tamanho de partícula do pó de vidro forneça informações quanto ao comportamento do tamanho e formato de poros e em relação às características de densidade e variação volumétrica dos produtos obtidos.

\section{MATERIAIS E MÉTODOS}

Para a obtenção dos corpos de prova (CPs) foi utilizado vidro de garrafa moído e peneirado, sendo o tamanho de partículas previamente medido com equipamento Microtac e apresentados os valores na Tabela 1 . A fim de se manter a padronização da composição do vidro, foram utilizadas garrafas da mesma marca (HEINE$\mathrm{KEN}^{\circledR}$ ). Na Tabela 2 é apresentado o resultado de FRX, realizado em equipamento Shimatdzu, modelo XRF1800, da composição química do vidro utilizado, o qual apresenta óxido de silício como componente principal $(72,5 \%)$, seguido pelo óxido de cálcio $(18,6 \%)$. A coloração verde da garrafa pode ser justificada pela presença de óxido de ferro em sua composição $(1,5 \%)$.

Tabela 1: Distribuição granulométrica do vidro.

\begin{tabular}{c|c|c}
\hline \multicolumn{3}{|c}{ D50 $(\boldsymbol{\mu m})$} \\
\hline$\# 100$ & $\# \mathbf{2 0 0}$ & $\# 325$ \\
\hline 15,5 & 11 & 4 \\
\hline
\end{tabular}


Tabela 2: Composição química do vidro de garrafa.

\begin{tabular}{c|c|c|c|c|c|c|c|c|c}
\hline \multicolumn{1}{c}{ ÓXIDOS CONSTITUINTES (\%) } \\
\hline $\mathrm{SiO}_{2}$ & $\mathrm{CaO}$ & $\mathrm{Na}_{2} \mathrm{O}$ & $\mathrm{Al}_{2} \mathrm{O}_{3}$ & $\mathrm{Fe}_{2} \mathrm{O}_{3}$ & $\mathrm{~K}_{2} \mathrm{O}$ & $\mathrm{Cr}_{2} \mathrm{O}_{3}$ & $\mathrm{MgO}$ & $\mathrm{SO}_{3}$ & $\mathrm{TiO}_{2}$ \\
72,53 & 18,62 & 2,13 & 2,07 & 1,49 & 0,85 & 0,71 & 0,55 & 0,36 & 0,24 \\
\hline
\end{tabular}

Cascas de ovos foram utilizadas como fonte de carbonato de cálcio [14,15], e são compostas de carbonato de cálcio (94\%), carbonato de magnésio (1\%), fosfato de cálcio (1\%) e matéria orgânica (4\% em massa). As cascas de ovos recebidas de um estabelecimento comercial local foram limpas e secas em estufa, a uma temperatura de $100^{\circ} \mathrm{C}$, por $24 \mathrm{~h}$. Após a secagem foram moídas em moinho planetário marca Servitech CT-241 e peneiradas em peneira \#325.

Como aditivo de prensagem dos corpos de prova, PVA foi utilizado. Para isso foi feita uma solução de $10 \%$ em massa do PVA (marca Synth) em água.

\subsection{Preparo dos corpos de prova}

Os CPs foram confeccionados com 3\% e 5\% em massa de casca de ovo \#325 (agente espumante), utilizando vidros \#100, \#200 e \#325. A mistura dos componentes (agente espumante e vidro moído) foi realizada em moinho planetário por 5 minutos. Após, foram adicionados $8 \%$ em massa da solução de PVA (ligante) à mistura para a confecção dos corpos de prova. As misturas foram, então, granuladas em peneira \#20 e armazenadas em sacos plásticos fechados por 30 minutos, para melhor homogeneização da umidade. Após isso, os CPs foram prensados em prensa uniaxial, com pressão de $40 \mathrm{MPa}$, em uma matriz de aço de dimensões 83 x 12 x $44 \mathrm{~mm}$.

Os CPs foram então deixados para secar, ao ambiente, por $24 \mathrm{~h}$ e, posteriormente, secos em estufa, a $100{ }^{\circ} \mathrm{C}$, por mais 24 horas. Para a sinterização foram utilizadas temperaturas de $700{ }^{\circ} \mathrm{C}, 800{ }^{\circ} \mathrm{C}$ e $900{ }^{\circ} \mathrm{C}$, com taxa de aquecimento de $2,5^{\circ} \mathrm{C} / \mathrm{min}$. e tempo de patamar de 30 minutos, sendo feitas três amostras para cada temperatura e percentual de agente espumante. As amostras foram nomeadas conforme o exemplo da Figura 1.

\section{\#325 T800 3\%}

\begin{tabular}{|ll|}
\hline Mesh do vidro $\quad$ Termperatura $\quad$ Percentual de casca de ovo \\
\hline
\end{tabular}

Figura1: Nomenclatura adotada para as diferentes amostras.

\subsection{Caracterização}

A análise das fases formadas nos diferentes CPs foi realizada pela técnica de difração de raios X (DRX), utilizando um difratômetro Bruker, modelo D2 Advance, com tubo de cobre (radiação K $\alpha=1,5418$ Á). A velocidade de varredura do goniômetro foi de $0,02^{\circ} / \mathrm{s}$, sendo o intervalo de varredura de $5^{\circ}$ a $70^{\circ}$. Também foram avaliados o formato e diâmetro médio dos poros, a expansão volumétrica e a densidade das diferentes amostras. Para aferição dos diâmetros de poros foi utilizado o software ImageJ. Para tanto, os CPs foram serrados ao meio e fotografados com um material de dimensões conhecidas como referência.

Os valores de expansão volumétrica foram calculados a partir da Eq. (1):

$$
E V=\frac{V f-V i}{V i} x 100
$$

Onde:

EV: expansão volumétrica;

Vi: volume inicial das amostras determinado com o auxílio de um paquímetro (amostra não sinterizada); Vf: volume final determinado pelo método de deslocamento de massa (amostra sinterizada). 
A determinação do volume dos CPS por deslocamento de massa foi realizada utilizando uma proveta de 1 Litro de volume e areia fina como material de preenchimento. A peça de forma irregular foi colocada dentro da proveta que, então, foi preenchida com areia até cobrir toda a amostra. Após isso, a peça é retirada da proveta e medida a diferença de volume na proveta.

A densidade foi avaliada utilizando-se os valores de volume pós-queima (Vf) e a massa do corpo de prova depois da queima. Para tanto foi utilizada a Eq. (2):

$$
\rho=\frac{m}{V}
$$

\section{RESULTADOS E DISCUSSÃO}

A avaliação da formação de fases cristalinas é apresentada nas Figuras 2 e 3. Na Figura 2A estão relacionados os difratogramas para as diferentes formulações que foram sinterizadas a $700{ }^{\circ} \mathrm{C}$. Nessa temperatura há uma preponderância da fase amorfa, perceptível pelo formato do gráfico e quase total ausência de padrões de difração. A única exceção é um máximo de difração de uma cristalização insipiente na amostra com vidro mais fino (\#325).

SASMAL et al. [16] mostraram que é esperada a ocorrência de cristalização em espumas vítreas derivadas de vidro reciclado, formulados com pós de tamanho de partícula fino. Essa pequena cristalização pode ser explicada pela maior reatividade do pó de vidro nessa formulação, o que permite que as reações de fusão e cristalização ocorram em temperaturas mais baixas do que nas outras formulações. A identificação de fases cristalinas wollastonita e devitrita só são possíveis a partir da temperatura de $800{ }^{\circ} \mathrm{C}$ (Figura $2 \mathrm{~B}$ e $2 \mathrm{C}$ ). Percebe-se, nessas temperaturas, uma independência do fator tamanho de partículas do vidro, pois para os CPs formulados com \#100, \#200 e \#325 houve semelhante desvitrificação das amostras. O fenômeno de desvitrificação pode ser justificado pela presença de $\mathrm{CaO}$, que em temperaturas mais elevadas reduz a solubilidade de fases vítreas, favorecendo a desvitrificação [17]. A devitrificação é esperada em espumas vítreas produzidas a partir de resíduos de vidro reciclado [18]. No que tange às fases presentes, a Figura 3 apresenta, de forma mais clara, a formação das fases wollastonita e devitrita para ambas as temperaturas.

A Figura 4 ilustra um exemplo dos formatos e distribuição de poros observados nas diferentes amostras. De acordo com a característica dos poros formados, houve a coalescência dos poros e formação de poros interconectados.

A Tabela 3 mostra os resultados dos diâmetros médios de poros nas diferentes formulações preparadas. Pode-se observar que as formulações com vidro \#325 apresentaram uma boa homogeneidade de diâmetro médio de poros, principalmente quando se compara o desvio-padrão (DP) dos CPs sinterizados a $800{ }^{\circ} \mathrm{C}$ e $900{ }^{\circ} \mathrm{C}$. Outra observação importante é de que o percentual de agente espumante provavelmente influencia no diâmetro médio de poro e desvio-padrão. As formulações com $5 \%$ de agente espumante obtiveram sempre menor diâmetro médio de poro, assim como menor desvio-padrão dessa medida. 


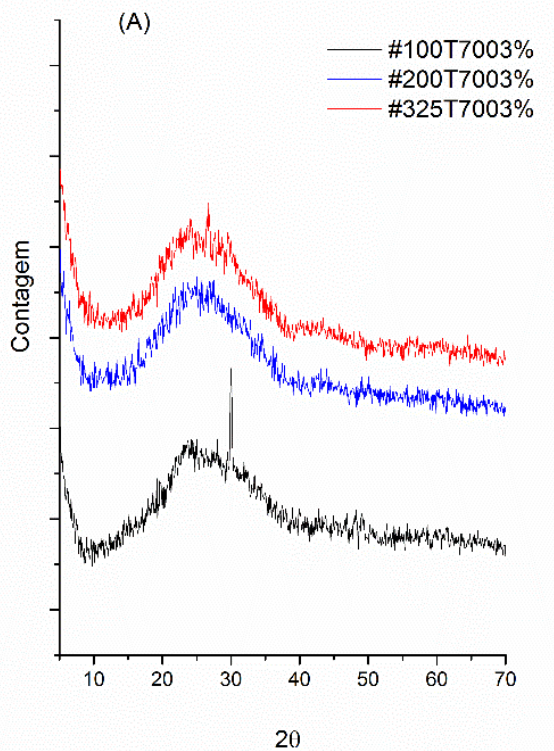

20

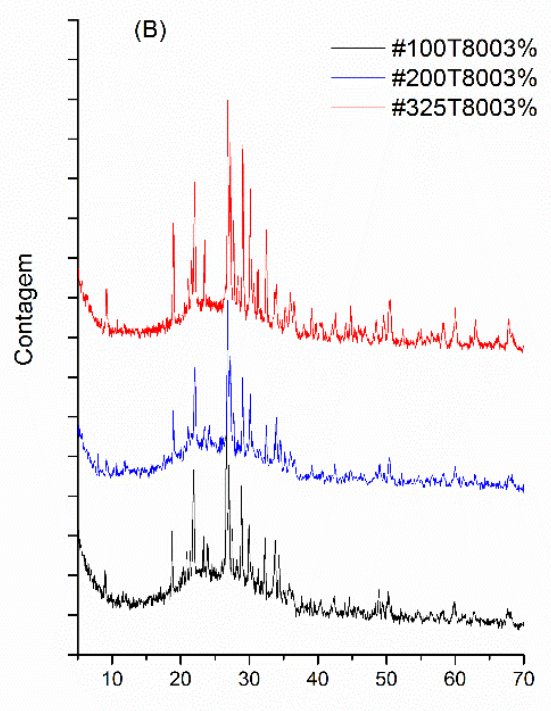

20

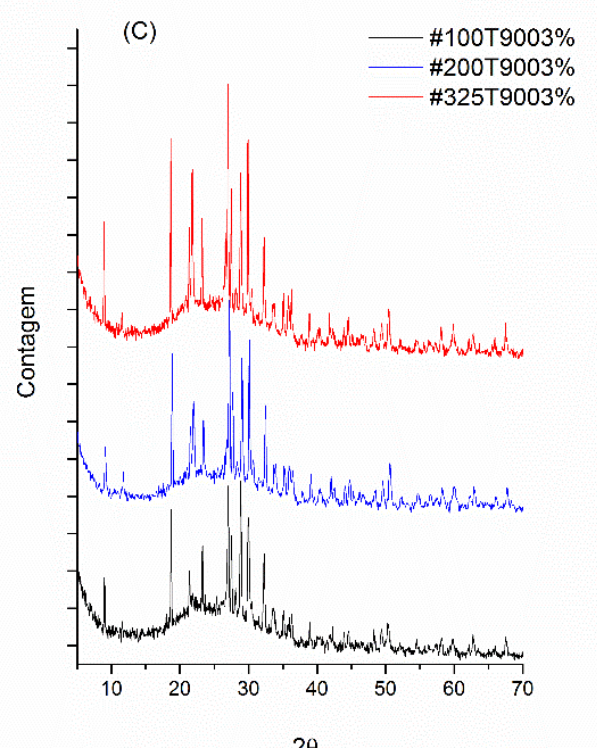

$2 \theta$

Figura 2: Gráficos comparativos das difrações de raios-X realizadas nas diferentes formulações. (a): $700{ }^{\circ} \mathrm{C},\left(\right.$ b) $800{ }^{\circ} \mathrm{C}$ e (c) $900{ }^{\circ} \mathrm{C}$. 


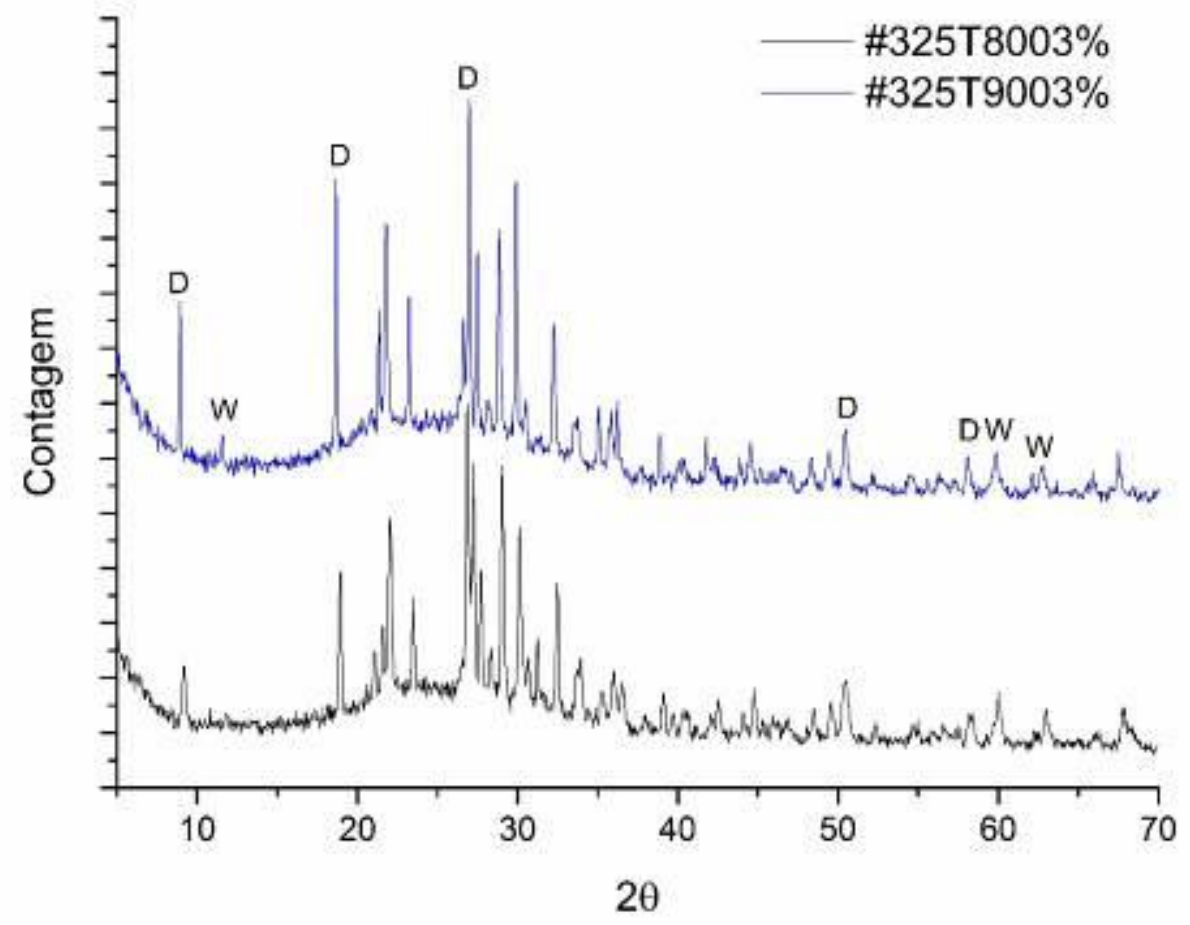

Figura 3: Difratogramas de raio-X obtidos para as amostras \#325, temperatura de $800{ }^{\circ} \mathrm{C}$ e $900{ }^{\circ} \mathrm{C}$, com adição de $3 \%$ de agente espumante. Legenda: W= wollastonita (JPCDS 43-1460); D= devitrita (JPCDS 23-0671).

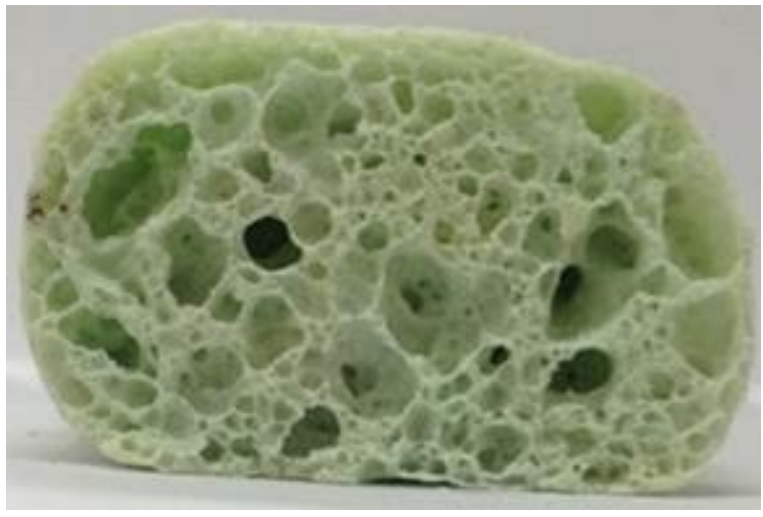

Figura 4: Fotografia da formação de poros para a amostra \#325T9003\%. 
Tabela 3: Diâmetro médio de poros e desvio-padrão para amostras com melhor expansão.

\begin{tabular}{c|c|c}
\hline AMOSTRA & DIÂMETRO MÉDIO (mm) & DESVIO-PADRÃO (mm) \\
\hline \#200T8003\% & 2,264 & 0,880 \\
\hline \#200T8005\% & 1,957 & 0,767 \\
\hline \#200T9003\% & 2,900 & 1,435 \\
\hline \#200T9005\% & 2,211 & 1,134 \\
\hline \#325T7003\% & 0,478 & 0,193 \\
\hline \#325T7005\% & 1,100 & 0,781 \\
\hline \#325T8003\% & 2,233 & 0,830 \\
\hline \#325T8005\% & 1,736 & 0,761 \\
\hline$\# 325 T 9003 \%$ & 1,943 & 0,940 \\
\hline$\# 325 T 9005 \%$ & 1,907 & 0,828 \\
\hline
\end{tabular}

Na Figura 5 é apresentado um gráfico do tipo boxplot da dispersão dos tamanhos médios de poros. Pode-se observar que houve uma maior homogeneidade dos poros na amostra \#325T9005\%. Essas mesmas características não foram observadas nas amostras com maior tamanho de partícula de vidro. Observou-se nas amostras (a exceção \#200T8005\%) um deslocamento da mediana (em relação ao $1^{\circ}$ e $3^{\circ}$ quartis), indicando a menor homogeneidade e distribuição dos poros. De uma forma geral, os CPs com 3\% de aditivo alcançaram maior taxa de espumação, em relação aos CPs formulados com 5\%. Durante o processo de espumação, as partículas do agente espumante se depositam na matriz vítrea e o $\mathrm{O}_{2}$ formado se difunde para o interior dos poros. No entanto, se a formação de $\mathrm{O}_{2}$ for mais rápida que sua difusão, a matriz vítrea se torna supersaturada. Como consequência, a nucleação dos poros pode ser homogênea ou heterogênea [8]. A homogeneidade da distribuição do tamanho dos poros aumenta quando da equivalência entre tamanho médio de partícula do pó de vidro e do agente espumante [9].

Os resultados das expansões volumétricas das amostras formuladas com 3\% e 5\% de agente espumante, em função da temperatura de queima e do tamanho de partícula, são apresentados na Figura 6. Os CPs formulados com vidros \#100 sofreram retração volumétrica para todas as temperaturas de queima, devido à sinterização das peças sem o aprisionamento adequado de $\mathrm{CO}_{2}$ que deve ter escapado da amostra antes do amolecimento do vidro. As amostras com vidro \#200 e \#325, sinterizadas à temperatura de $700{ }^{\circ} \mathrm{C}$ apresentaram uma baixa expansão, ficando abaixo de $200 \%$. Esse comportamento pode estar relacionado ao agente espumante ser liberado antes de alcançar uma viscosidade mínima para sua captura e expansão dentro da massa vítrea. A $900{ }^{\circ} \mathrm{C}$ ocorreram as maiores expansões dos CPs (aproximadamente 677,45\% para \#200T9003\% , 550\% para \#3259003\%). Espumas vítreas produzidas com até 3\% de agente espumante podem ser produzidas, de tal forma que se alcance uma densidade adequada. A utilização de maior percentual em massa de aditivo pode favorecer a cristalização, fazendo com que se aumente a viscosidade, limitando, dessa forma, a capacidade de expansão do sistema vítreo. Por consequência, a densidade aparente também aumentaria [19].

A significativa menor espumação verificada para os corpos cerâmicos formulados com a maior granulometria provavelmente se dá pela maior fuga de $\mathrm{CO}_{2}$ antes que o corpo cerâmico vitrificasse e o aprisionasse nos poros fechados. Devido à decomposição térmica do $\mathrm{CaCO}_{3}$ se dar a partir de uma temperatura acima de $630{ }^{\circ} \mathrm{C}$, uma maior reatividade, ou seja, uma menor temperatura de vitrificação, é recomendada. A menor granulometria gera uma maior área, e isso favorece a cinética de vitrificação do material [9,18]. Por outro lado, com a diminuição do tamanho de partícula do vidro, ocorre aumento da interação entre as partículas deste e do agente espumante. Sendo assim, a diminuição da temperatura necessária a ser empregada na sinterização do vidro é esperada [6]. A influência da granulometria do vidro no processo de espumação do corpo cerâmico pode ocorrer tanto na decomposição do agente espumante quanto no processo de formação de fase vítrea, visto que uma partícula menor apresenta maior reatividade, atuando nas reações químicas do silicato com o agente espumante, assim como diminuindo a temperatura necessária para sua fusão e vitrificação [9].

Os valores de densidade, calculados a partir da Eq. (2), são apresentados na Figura 7. A menor densidade foi obtida na amostra \#325T8003\% $\left(0,18 \mathrm{~g} / \mathrm{cm}^{3}\right)$. Esse valor está próximo do produto comercial FOAMGLAS $^{\circledR}$ T4, comercializado pela Pittsburgh Corning Europe $N V$ como isolante térmico, e que apresenta uma densidade de $0,117 \mathrm{~g} / \mathrm{cm}^{3}$ [20]. Considerando que o material desenvolvido em laboratório utilizou $100 \%$ de resíduos domésticos e comerciais, e comparando-o ao produto FOAMGLAS ${ }^{\circledR} \mathrm{T} 4$, o qual utiliza apenas 
$60 \%$ de resíduos, o resultado pode ser considerado bastante satisfatório. Além disso, as espumas de vidro comerciais apresentam uma faixa de densidade tipicamente de 0,1 a $0,3 \mathrm{~g} / \mathrm{cm}^{3}[3]$.

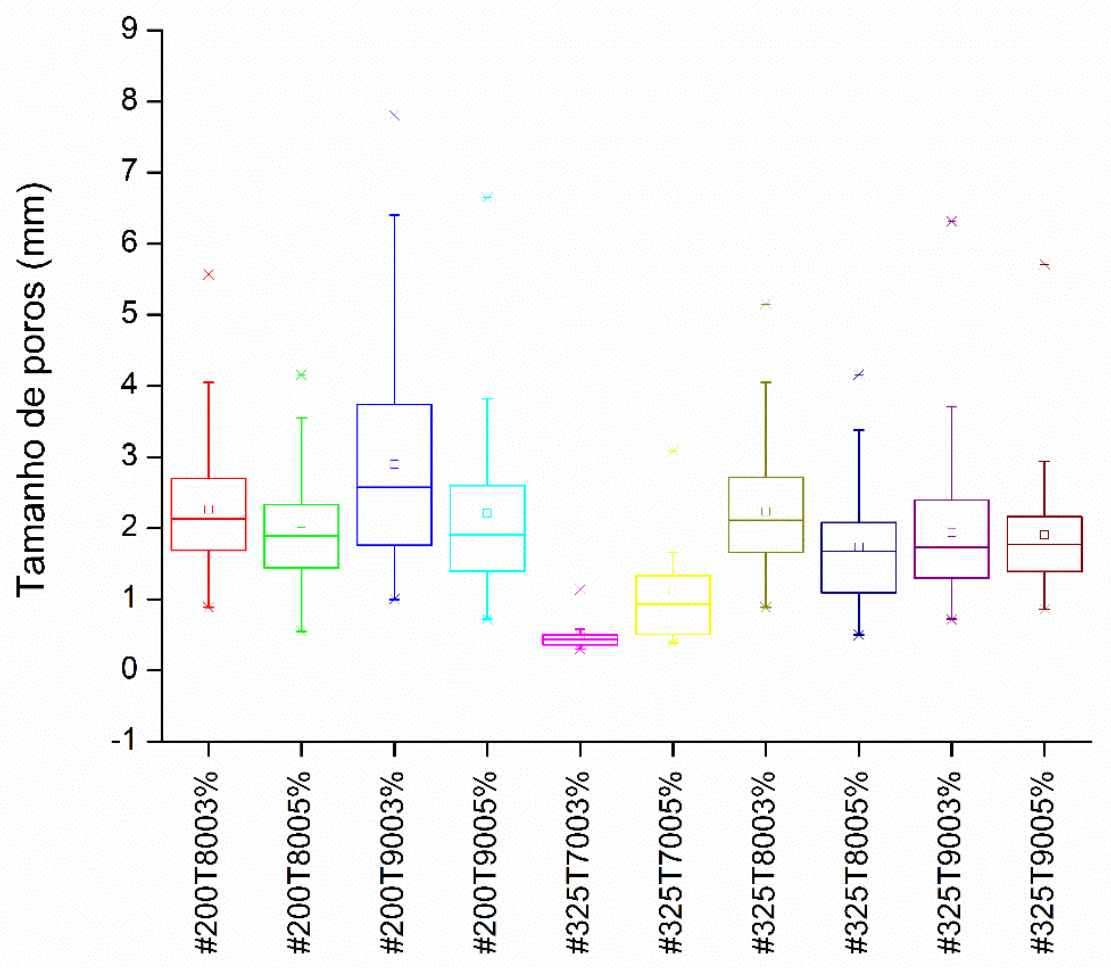

Figura 5: Gráfico da distribuição dos tamanhos médios de poros para as diferentes formulações de espumas vítreas. 


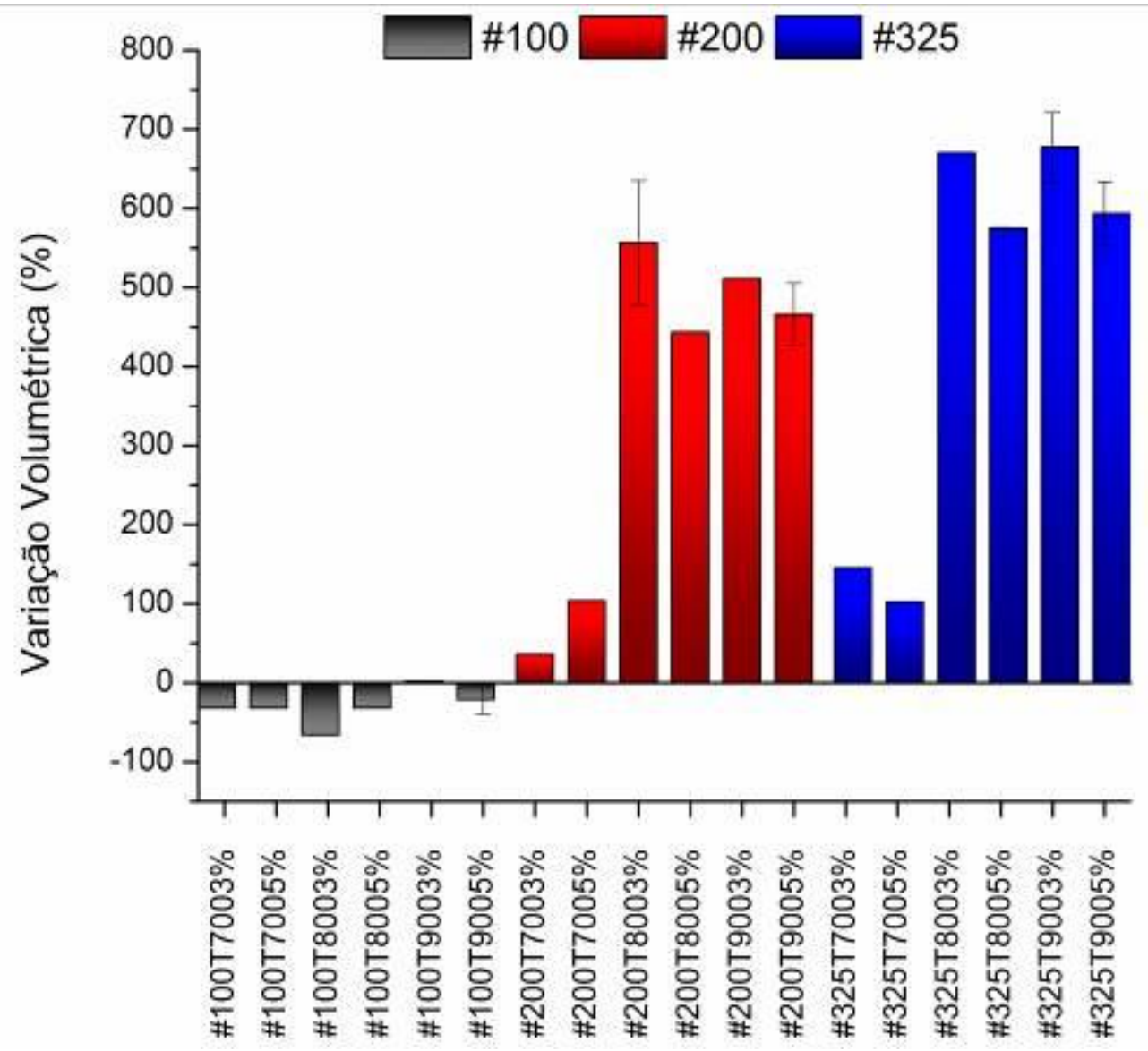

Figura 6: Gráfico da variação volumétrica das diferentes formulações empregadas no desenvolvimento das espumas vítreas. 


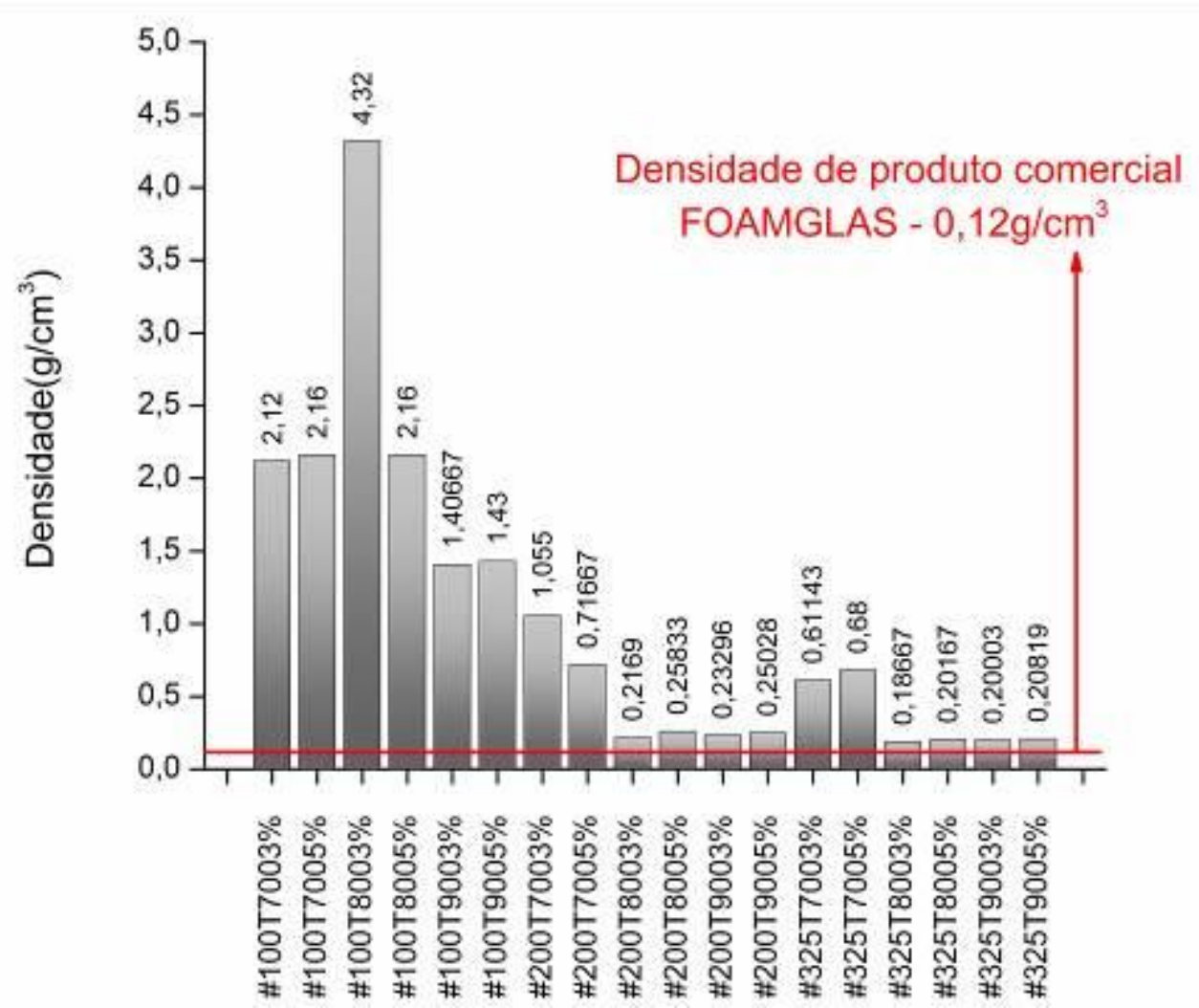

Figura 7: Gráfico da variação de densidade das diferentes formulações empregadas no desenvolvimento das espumas vítreas.

\section{CONCLUSÕES}

Com base nos resultados obtidos, pode-se concluir que foi possível obter espumas vítreas utilizando apenas matérias-primas recicladas. A análise de DRX mostrou que ocorre a formação de fases cristalinas somente acima de $800{ }^{\circ} \mathrm{C}$, devido à desvitrificação das peças, com a formação das fases cristalinas wollastonita e devitrita. A variação da proporção de agente espumante revelou que com $3 \%$ em massa é possível obter maior expansão volumétrica, porém, com 5\% em massa, obtêm-se poros menores e mais homogêneos. O valor de densidade está dentro da faixa aplicada na indústria; contudo, a homogeneidade dos tamanhos de poros pode ser aprimorada. Também é possível ressaltar a grande influência do tamanho de partícula do vidro, em que menores tamanhos de partículas favorecem o processo de espumação, como foi observado na maior expansão volumétrica e menor densidade das amostras preparadas com os vidros \#325.

\section{BIBLIOGRAFIA}

[1] CEMPRE - Compromisso Empresarial para a Reciclagem, http://www.cempre.org.br. Acessado em março de 2014.

[2] PASCAL, G.Y., FRANÇOIS, O.M., "Characterization of lead, barium and strontium leachability from foam glasses elaborated using waste cathode ray-tube glasses”, Journal of Hazardous Materials, v. 185, pp. 236-241, 2011.

[3] MUGONI, C., MONTORSI, M., "Design of glass foams with low environmental impact", Ceramics International, v. 41, pp. 3400-3408, 2015.

[4] SPIRIDONOV, Y.A., ORLOVA, L.A., "Problems of foam glass production", Glass and ceramics, v. 9, pp. 313-314, 2003.

[5] POKORNY, A., VICENZI, J., BERGMANN, C.P., "Influence of Heating Rate on the Microstructure of Glass Foams”, Waste Management \& Research (ISWA), v. 1, pp. 1-8, 2010. 
[6] KONIG, J., PETERSEN, R. R., YUE, Y., "Influence of the glass-calcium carbonate mixture's characteristics on the foaming process and the properties of the foam", Journal of the European Ceramic Society, v.1, n.6, pp. 1591-1598, Jun. 2014.

[7] KONIG, J., PETERSEN, R. R., YUE, Y., "Gas-releasing reactions in foam-glass formation using carbon and $\mathrm{Mn}_{\mathrm{x}} \mathrm{O}_{\mathrm{y}}$ as the foaming agents", Ceramics International, v.43, n.5, pp. 4638-4646, Apr. 2017.

[8] PETERSEN, R. R., KONIG, J., "The mechanism of foaming and thermal conductivity of glasses foamed with $\mathrm{MnO}_{2}$ ", Journal of Non-Crystalline Solids, v. 425, pp. 74-82, Oct. 2015.

[9] POKORNY, A., Obtenção e caracterização de espumas vítreas a partir de resíduos de vidro sodocálcico e calcário dolomítico como agente espumante, Dissertação de M.Sc., PPGE3M/UFRGS, Porto Alegre, RS, Brasil, 2006.

[10] LEE, S. S, et al. "Heavy metal immobilization in soil near abandoned mines using eggshell waste and rapeseed residue”, Environmental Science and Pollution Research, v. 20, n.3, pp 1719-1726, Mar. 2013.

[11] BALÁŽ, M., FICERIOVÁ, J., BRIANČIN, J., "Influence of milling on the adsorption ability of eggshell waste", Chemosphere, v.146, pp.458-471, Mar. 2016.

[12] GOMES, L. C., DI LELLO, B. C., CAMPOS, J. B., SAMPAIO, M., "Síntese e caracterização de fosfatos de cálcio a partir da casca de ovo de galinha", Cerâmica, v.58, n.348, pp.448-452, 2012.

[13] HO, W., HSU, H.C., HSU, S.K., et al., "Calcium phosphate bioceramics synthesized from eggshell powders through a solid state reaction”, Ceramics international, v.39, n.6, pp. 6467-6473. Aug. 2013.

[14] MURAKAMI, F. S., RODRIGUES, P. O., "Physicochemical study of $\mathrm{CaCO}_{3}$ from egg shells", Ciência e Tecnologia de Alimentos", v.27, n. 3, 2007.

[15] CALIMAN, L. B., Síntese e caracterização de hidroxiapatita obtida a partir da casca de ovo de avestruz, Dissertação de M.Sc., PROPEMM/IFES, Vitória, ES , Brasil, 2011.

[16] SASMAL, N., GARAI, M., KARMAKAR, B., "Preparation and characterization of novel foamed porous glass-ceramics", Materials Characterization, v. 103, pp. 90-100, 2015.

[17] ORTUÑO, Á.V., Introducción a la química industrial, 2 ed., Barcelona, Reverté, 1994.

[18] BERNARDO, E., et al., "Recycling of waste glasses into partially crystallized glass foams", Journal of Porous Materials, v. 17, n. 3, pp. 359-365, 2010.

[19] FERNANDES, H. R., TULYAGANOV, D. U., FERREIRA, J. M. F., "Preparation and characterization of foams from sheet glass and fly ash using carbonates as foaming agents", Ceramics International, v. 35, n. 1, p. 229-235, 2009.

[20] PITTSBURGH CORNING EUROPE NV.,

http://uk.foamglas.com/__frontend/handler/document.php?id=132\&type=42. Acessado em 28 de junho de 2016.

\section{ORCID}

Fabrício Ravanello Mariosi

Luiz Fernando Rodrigues Junior

Rubens Camaratta

Fernando Machado http://orcid.org/0000-0002-2510-5146

https://orcid.org/0000-0002-5753-5503

https://orcid.org/0000-0002-6780-1801

https://orcid.org/0000-0001-9463-3535 